\title{
Perceptions and experiences of promotoras and pharmacists in an academic-community partnership providing telephonic MTM services to a Spanish-speaking, rural population: a focus group study
}

\author{
Blanca Guerra, PharmD; Shannon Vaffis, MPH; David R Axon, PhD, MPharm, MS; Sandra Leal, PharmD, MPH, FAPhA; \\ Terri Warholak, PhD, RPh, FAPhA; Ann M Taylor, MPH, MCHES; and Nicole Scovis, PharmD
}

\section{What is already known about this subject}

- Promotoras are Hispanic/Latino lay health workers who assist patients in their communities by serving as intermediaries between medical providers, pharmacists, and other clinical staff.

- In 2014, an academic-based medication management center began collaborating with community clinics and independent pharmacies to provide telephonic medication therapy management (MTM) services to patients in rural Arizona as part of the Rural Arizona Medication Therapy Management (RAzMTM) program.

- Limited data exist regarding the collaboration between pharmacist/ pharmacy interns and promotoras in health care settings.

\section{What this study adds}

- This study provided insight into the perceptions and opinions of pharmacist/ pharmacy interns and promotoras who participated in the RAzMTM program.

- This study adds to the body of literature on strategies to improve collaborative care using pharmacists/pharmacy interns, promotoras, and other health care providers.

\section{ABSTRACT}

BACKGROUND: The literature is limited concerning the collaboration between pharmacists and promotoras in the delivery of medication therapy management (MTM) services. Yet, this information could help address a practice gap while improving MTM collaborative care approaches.

OBJECTIVE: To identify the knowledge, attitudes, and barriers of clinical call center health professionals (pharmacists, nurses, pharmacy interns) and promotoras towards MTM collaborative care in implementing the Rural Arizona Medication Therapy Management (RAzMTM) program.

METHODS: A descriptive, qualitative study using semistructured focus groups was conducted with call center health professionals and promotoras who participated in the RAzMTM program to improve pharmaceutical care for patients with diabetes and/or

\section{Author affiliations}

Blanca Guerra, PharmD, University of Arizona College of Pharmacy and SinfoniaRx, Tucson, AZ. Shannon Vaffis, MPH; David R Axon, PhD, MPharm, MS; Terri Warholak, PhD, RPh, FAPhA; and Ann M Taylor, MPH, MCHES, University of Arizona College of Pharmacy, Tucson. Sandra Leal, PharmD, MPH, FAPhA, SinfoniaRx, Tucson, $A Z$, and Nicole Scovis, PharmD, Tabula Rasa HealthCare, Tucson, AZ.

AUTHOR CORRESPONDENCE: Shannon Vaffis, 716.907.6022, vaffis@pharmacy.arizona.edu

J Manag Care Spec Pharm 2020;26(11):1390-97

Copyright $@ 2020$, Academy of Managed Care Pharmacy. All rights reserved.

hypertension in rural Arizona. Recruitment and consent letters, a demographic questionnaire, and a focus group guide were designed specifically for this project. Three facilitators participated in each focus group-one guided the discussion while the others took notes. Focus groups were audio recorded to verify all responses and transcribed verbatim with omission of participant identifiers. Thematic analysis was conducted by 2 independent researchers who reviewed the transcripts to 
identify codes, seek consensus, and agree on themes, with negotiation from a third independent researcher.

RESULTS: Nine participants took part in 2 focus groups. Participants were predominantly female (89\%), college graduates and/or had postgraduate/professional degrees (78\%), and were Hispanic or Latino (89\%). Five themes were identified: (1) roles and responsibilities of RAzMTM participants; (2) benefits unique to the RAzMTM program; (3) interprofessional experience of RAzMTM participants; (4) professional growth for RAzMTM participants; and (5) opportunities for future improvement. Perceptions of the participants in the RAzMTM program were consistent-experiences of health professionals and promotoras were positive; they recognized the benefit of each other's involvement in the program; and they learned how to work together to improve patient care. Future recommended program improvements include improving ease of scheduling (e.g., extending pharmacist availability to provide MTM services).

CONCLUSIONS: These focus group results suggest that provision of telephonic MTM services, using an academic-community partnership, was positively received by participating pharmacists and promotoras. However, future work is needed for continued improvement of strategies to enhance interprofessional relationships in patient chronic disease management.

The published literature is limited regarding collaborative relationships between pharmacists and community health workers, or promotoras, in today's health care system and, more specifically, as it pertains to the provision of medication therapy management (MTM) services..$^{1-3}$ The Centers for Medicare \& Medicaid Services mandate and oversee health plans to ensure that they provide MTM services to Medicare-eligible patients who meet these qualification criteria: having 2 or more chronic conditions, taking 2 or more chronic medications, and medication costs above an annually specified threshold. Plan sponsors may also offer services beyond these minimum criteria. ${ }^{4}$ To help patients manage their chronic conditions and medications, MTM encompasses comprehensive medication management services, which includes comprehensive medication reviews (CMRs), medication reconciliation, and adherence to national consensus guidelines. ${ }^{4,5}$

A growing body of literature illustrates the efficacy of MTM in improving patient-related health measures and lowering health care costs. ${ }^{1-3}$ Collaborations between pharmacists and other health professionals (such as promotoras) have been shown to increase benefits of MTM to patients. ${ }^{6}$

Promotoras, also commonly referred to as community (lay) health workers or advisors, outreach workers, patient navigators, or peer leaders, are trusted members of the Hispanic/Latino communities that are common in southern Arizona. ${ }^{7}$ These individuals are sought out and highly respected because they understand the important situations and circumstances of their fellow community members, since they often live in the communities they serve. ${ }^{7}$ While these individuals have played an important role in their respective communities for some time, only more recently has their role and status in their communities become more fully recognized. ${ }^{6-9}$

Despite the recognition of the contributions of promotoras in the provision of health care services, their roles vary widely in different settings (e.g., patient education, home visits, and communicating and translating between patients and providers). ${ }^{6-9}$ To this end, the Centers for Disease Control and Prevention published a document providing guidance and resources for implementing recommendations for integrating promotoras into community-based efforts in chronic disease prevention. ${ }^{7}$ However, the evidence supporting this innovative practice does not include mention of the collaboration specifically between pharmacists and promotoras. Nevertheless, efforts are underway to establish standards to allow promotoras to serve as members of the interprofessional team in some health care settings.?

In Arizona, a novel program exists whereby promotoras engage patients in MTM services through patient recruitment, home visits, and ensuring patient understanding of recommendations. ${ }^{6}$ Yet, a gap still exists regarding the role that promotoras can play in helping patients manage their chronic conditions and associated medications with the provision of pharmacist-delivered MTM services. Thus, the purpose of this qualitative study was to describe the perceptions and experiences of pharmacists, nurses, pharmacy interns, promotoras, and other professionals pertaining to their involvement in an academic-community partnership to deliver MTM services as part of the Rural Arizona MTM (RAzMTM) program.

\section{Methods}

\section{RURAL ARIZONA MTM PROGRAM DESCRIPTION}

In 2014, an academic medication management center began collaborating with community clinics and independent pharmacies to provide telephonic MTM services to eligible Medicare patients with diabetes and/or high blood pressure in rural Arizona, as part of the RAzMTM program. The partner clinic integrated promotoras into service delivery to assist patients with multiple chronic conditions. The role of the promotoras was to act as a patient advocate and serve as the link between the medication management center staff and patients. ${ }^{8}$ 


\section{TABLE 1 Focus Group Discussion Items Regarding Involvement in the RAzMTM Program}

Work experience

Tell me about your work experience during the RAzMTM program.

Probe: What was a typical workday for you during the RAzMTM program?

Probe: What were your responsibilities during the RAzMTM program?

\section{Benefit or value}

What benefit or value did you observe during the RAzMTM program?

(For patients, promotoras, pharmacist/pharmacy interns, or other health care providers?)

Probe: What worked well?

Probe: What didn't work well?

Probe: What positive aspects did you detect?

Probe: What negative aspects did you detect?

Improvements and knowledge

What can be improved?

Probe: How can the program be improved?

Probe: What did you learn about the role of the pharmacist? Promotora?

Probe: What changed about your perception of what a pharmacist does? Promotora?

Probe: Did this program change the way you interact with pharmacists? Promotoras?

Professional development

Has working with the RAzMTM program helped your professional development? If so, how?

Probe: Has working with the RAZMTM program helped you gain professional development attributes or characteristics (e.g., commitment, confidence, independence, motivation, and communication)? If so, how?

Probe: Can you give an example where you have observed or experienced professional behavior?

Probe: Do you feel the program helped you become more comfortable with medications used to treat chronic conditions?

\section{Closure}

Is there anything we missed that you would like to talk about?

What is the most important point we discussed?

RAzMTM=Rural Arizona Medication Therapy Management Program.

\section{STUDY DESIGN}

The current qualitative study used focus groups composed of call center health care professionals (pharmacists, pharmacy interns, and a nurse) and promotoras to obtain individual and collective perceptions and experiences regarding the RAzMTM pilot program. Separate focus groups were conducted for the pharmacists, interns, and nurse and the promotoras, along with the compliance manager. Thus, the focus groups provided an opportunity to allow participants to openly discuss their opinions, describe their understanding of each other's roles, and identify facilitators and barriers. The University of Arizona Institutional Review Board approved this study, and it was deemed exempt, or not human subjects research.

\section{ELIGIBILITY AND RECRUITMENT}

Individuals were eligible to participate in this focus group study if they were part of the RAzMTM health care professional or administrative staff (pharmacist, pharmacy intern, nurse, quality assurance compliance manager, or promotora) who participated in the RAzMTM program between 2014 and 2018. Eligible participants were identified via existing contacts provided by the lead pharmacist in the RAzMTM program. A recruitment letter was sent via email to eligible participants 4 weeks before the planned start date of the focus groups. All participants provided informed consent before the focus groups began.

\section{DISCUSSION QUESTIONS}

Focus group questions were developed specifically for this study by the research team, using previous focus group discussions that elicited perceptions and experiences of participants. ${ }^{10}$ Four core questions, developed with prompts and probes to aid the discussion, included inquiries about participants' work experiences during the RAzMTM program; the benefits or value they observed during the program; the knowledge of and improvements to the program; and the participants' professional development during the RAzMTM program. The focus group guide questions were prepared in English and Spanish. See Table 1 for more details.

\section{DEMOGRAPHIC QUESTIONNAIRE}

A short, online demographic questionnaire was created using SurveyMonkey software (San Mateo, CA). The questionnaire contained 6 items: age, gender, race, ethnicity, education, and postgraduate education. Participants were given the link to the questionnaire and asked to complete it at the end of the focus group session. 


\section{TABLE 2 Themes Identified and Participant Responses to Discussion Questions Posed During the Focus Groups}

\section{Theme}

Roles and responsibilities of RAzMTM participants

\section{Participant Individual and Collective Responses}

- Pharmacist: "My participation was mostly the contact person for each site and conducting the patient reviews and then communicating my findings back to either the pharmacy or the clinic, of course, with the help of the nurses. I have been there from the beginning to the end, mostly providing clinical services and overseeing the interns who also helped with providing clinical services."

- Pharmacist: "We conducted/completed patient medication reviews, contacted promotora/patients, and reported findings/ interventions to the clinic. I served as preceptor to the pharmacy interns."

- Pharmacy intern: "I completed patient medication reviews (verify with pharmacist for final review), contacted promotora/ patient, and reported findings/interventions to the clinic."

- Nurse: "My role was more of coordination. I handled scheduling, and then after the completion of the medication review, I documented the outcomes so we could track the performance of the program. I also sent out letters to members, faxes to the prescribers, and followed up with calls to prescribers as needed."

- Nurse: "I served in a coordinator role, scheduling, documenting outcomes, and sending letters to patients."

- Promotora: "[Our role is to] Identify the patients that would potentially qualify and flag them for the day, then we would consult with the providers to confirm patients met criteria. We would then speak to the patient, explain the RAzMTM program, and schedule appointment for a telephone appointment with the call center professional. We also assisted in the appointments at the patient's home."

- Quality assurance compliance manger: "The promotoras did all the work; they identified the patients that would potentially qualify and flag them for the day; then they would consult with the providers to confirm patient met criteria. The promotoras would then speak to the patient, explain the RAzMTM program, and schedule a telephone appointment with the call center professional. The promotoras also assisted in the appointments at the patient's home."

Benefits unique to the RAzMTM program
- Pharmacist: "Being able to speak Spanish was very beneficial for the patients; 95\% of the patients only spoke Spanish."

- Pharmacy intern: "Something that I thought was pretty beneficial, we were able to experience with the promotoras, see exactly everything they're taking."

- Promotora: "I learned a lot; I did not know that the prescription bottles have the figure of the medication, the color, and that helps me in my other visits to check if the patient's medications are exactly what was prescribed."

- Promorota: "It was very beneficial, even more, I realized that now that time has passed and when I do another type of home visit with those patients, they still have that same discipline that they obtained during the calls from the program. I stay astonished because I see that they did really learn and that the program did work."

- Promotora: "We continue visiting patients and they tell us, 'yes, I already learned, remember you told me not to put my new medication in the older bottles; I first finish my medication in the older bottle and throw it away, then start my new bottle."

- Promotora: "I imagine the doctors benefited as well because their patients were more careful with their medications, and it is very important for their control, more than anything for their health."

continued on next page

\section{DATA COLLECTION}

One focus group was conducted at each of 2 different sites: an MTM call center and a community health clinic located in Arizona. The call center focus group included health care professionals ( 2 pharmacists, 3 pharmacy interns, and 1 nurse), and the community health center focus group involved 2 promotoras and a quality assurance compliance manager (who worked most closely with the promotoras in scheduling home visits and interfacing with the other health professionals on the project team). For both sessions, participants were given the option to join remotely via telephone; approximately half of participants in each group participated in person. Each focus group lasted approximately
60 minutes. Three facilitators attended each focus group: 1 facilitator guided the discussion (Guerra); the second and third facilitators (Vaffis, Axon) took notes and recorded the session while also helping to guide the discussion.

\section{DATA ANALYSIS}

Audio recordings of the focus groups were transcribed verbatim with omission of participant identifiers, using the online transcription service Rev (https://www.rev.com/). Two independent reviewers (Guerra, Vaffis) conducted thematic analysis of the transcripts via line-by-line coding, with individual codes aggregated into higher-level themes. A third reviewer (Axon) facilitated consensus among the reviewers for the final themes. 


\section{TABLE 2 Themes Identified and Participant Responses to Discussion Questions Posed During the Focus Groups (continued)}

\begin{tabular}{|c|c|}
\hline \multirow{5}{*}{$\begin{array}{l}\text { RAzMTM } \\
\text { participants' } \\
\text { interprofessional } \\
\text { experience }\end{array}$} & $\begin{array}{l}\text { - Pharmacist: "I think the promotoras did a great job mediating and sometimes when patient's clinical literacy was not there, } \\
\text { the promotoras took very good notes, even recap." }\end{array}$ \\
\hline & $\begin{array}{l}\text { - Pharmacist: "I think the biggest things I took away from this is you can have a remote clinical pharmacist be very much } \\
\text { embedded in these clinics and really the advocates of promotoras really driving a lot of the recommendations." }\end{array}$ \\
\hline & $\begin{array}{l}\text { - Pharmacy intern: "I didn't really know what their positions were, so it was nice to see that they were kind of like the } \\
\text { advocate for the patient." }\end{array}$ \\
\hline & $\begin{array}{l}\text { - Pharmacy intern: "They played a big role with making sure that any concerns, communication, and even getting their } \\
\text { medications at the pharmacy." }\end{array}$ \\
\hline & $\begin{array}{l}\text { - Promotora: "It was so many things, she was very friendly and she did a great job making sure patients understood; she } \\
\text { educated them, left them a lot of education and for me too." }\end{array}$ \\
\hline \multirow{3}{*}{$\begin{array}{l}\text { Professional } \\
\text { growth for } \\
\text { RAzMTM } \\
\text { participants }\end{array}$} & $\begin{array}{l}\text { - Pharmacist: "I applied for to be a resident preceptor and on the application, there were questions asking about contribu- } \\
\text { tions to clinical programs; I was able to draw my experiences from this program." }\end{array}$ \\
\hline & $\begin{array}{l}\text { - Pharmacy intern: "I thought it was unique and helpful; I was in my second year of pharmacy school, and we still hadn't } \\
\text { covered all disease states like heart failure. I was pre-exposed before learning it in school from the pharmacist, which was } \\
\text { beneficial and helped my professional growth." }\end{array}$ \\
\hline & - Promotora: "I learned a lot about the side effects of medications, when the pharmacist was speaking to the patient." \\
\hline \multirow{4}{*}{$\begin{array}{l}\text { Opportunities } \\
\text { for future } \\
\text { improvement }\end{array}$} & $\begin{array}{l}\text { - Pharmacist: "I would encourage getting the doctors more involved at the start of the program so that they can feel they } \\
\text { have some ownership and we can explain to them what the program's intents are." }\end{array}$ \\
\hline & $\begin{array}{l}\text { - Pharmacy intern: Promotora/patient availability: "Sometimes when we called at the scheduled time they did not answer, } \\
\text { we had to call back at a later time." }\end{array}$ \\
\hline & $\begin{array}{l}\text { - Promotora: "A lot of patients work so sometimes the hours that were available, that the pharmacist was available were just } \\
\text { not working because obviously everybody was working, and we couldn't do the home visits during those times so towards } \\
\text { the end we were asking for more Fridays or later appointments or for the pharmacist to be available at later times." }\end{array}$ \\
\hline & $\begin{array}{l}\text { - Compliance quality assurance manager: "Pharmacist availability was not working for our patient population; everybody } \\
\text { was working, and we couldn't do the home visits during those times. We have also faced challenges in getting the patients } \\
\text { to see the providers, and for this reason, we have extended our clinic hours." }\end{array}$ \\
\hline
\end{tabular}

RAzMTM = Rural Arizona Medication Therapy Management Program.

\section{Results}

Nine individuals participated in 2 focus groups: pharmacists $(n=2)$, pharmacy interns $(n=3)$, nurses $(n=1)$, promotoras $(n=2)$, and a quality assurance compliance manager $(n=1)$. The sample was predominately female (89\%), Hispanic or Latino (89\%), and college graduates (78\%). The high proportion of female and Hispanic/Latino participants was inclusive of the promotoras, an exclusively female group from the local Hispanic/Latino community. The high proportion of college graduates included the health care professionals providing the MTM services.

Thematic analysis yielded 5 major themes: (1) roles and responsibilities of RAzMTM participants; (2) benefits unique to the RAzMTM program; (3) RAzMTM participants' interprofessional experience; (4) professional growth for RAzMTM participants; and (5) opportunities for future improvement. Participants provided specific examples of RAzMTM program benefits and opportunities for improvement. Representative quotes for each theme are presented in Table 2. Response saturation-the point when no new ideas or information emerges- was achieved, so no further sessions were needed. ${ }^{11}$

\section{THEME 1: ROLES AND RESPONSIBILITIES OF RAZMTM PARTICIPANTS}

The pharmacist's responsibilities were to conduct patient CMRs, contact the promotoras and patients, report their interventions to the clinic, follow up with patients, and serve as preceptor to the pharmacy interns. The interns reported having similar roles to the pharmacist, but they were under the supervision of the pharmacist.

The nurse's role was to handle scheduling and document outcomes following completion of the CMRs to track performance; they also sent out letters and facsimiles to the prescribers and followed up with telephone calls when warranted.

The promotoras' responsibilities were to identify/recruit patients, schedule the telephonic MTM appointments, 
assist during the appointments, and report findings to the provider.

The role of the quality assurance compliance manager was to verify that appropriate documentation was present in the electronic medical records and that pharmacist calls/ promotora visits were being scheduled for the patients who qualified for the program.

\section{THEME 2: BENEFITS UNIQUE TO THE RAZMTM PROGRAM}

Participants said that the RAzMTM program was beneficial; the call center health professionals (i.e., the pharmacists, interns, and nurse) said that having promotoras at patients' homes during the telephonic MTM appointments was valuable given that they were able to report how patients actually managed their medications at home.

The promotoras also said the program benefited the patients; they said patients retained much of the information provided by the pharmacists/pharmacy interns during the telephone MTM appointments.

\section{THEME 3: INTERPROFESSIONAL EXPERIENCES OF RAZMTM PARTICIPANTS}

Participants reported that their interprofessional experiences were instrumental in delivering telephonic MTM services to rural Arizonans. In particular, pharmacists commented that having a promotora present helped them communicate with patients from their remote location.

\section{THEME 4: PROFESSIONAL GROWTH FOR RAZMTM PARTICIPANTS}

Participants experienced professional growth during and after the pilot program. For example, 1 pharmacist commented that they were able to use their experiences from the RAzMTM program when applying to become a residency preceptor, while pharmacy interns gained clinical knowledge that they had not yet encountered in pharmacy school. As the pharmacists counseled patients about their medications, the promotoras were also able to learn about the medications that patients were using.

\section{THEME 5: OPPORTUNITIES FOR FUTURE IMPROVEMENT}

One consistent comment among the participants pertained to appointment scheduling-patients were sometimes out when the pharmacist or pharmacy intern called or the pharmacists were unavailable when the patient was home.

Another opportunity for improvement was to get providers involved initially. One pharmacist mentioned she had the opportunity to meet a provider at that clinic and was able to explain the program. She felt that after the conversation, the provider was more accepting of her recommendations.

\section{Discussion}

The findings of this focus group study offer important new insights into the value of collaborative, telephonic health care services. A previous evaluation of the RAzMTM program carried out in 2014 from a quantitative approach found that 237 medication-related problems were identified, and 1,1032 health promotion interventions were conducted by the interprofessional team for 517 patients. $^{8}$ This evaluation investigated the views of those who participated in the RAzMTM program from a qualitative perspective.

On the other hand, our focus group study looked at the perceptions of health professionals who were providing the MTM services. Previous work has looked at patient perspectives of the RAzMTM program using focus groups. ${ }^{10}$ This project followed a similar methodology using focus groups to explore the perceptions of different health care workers who participated in the RAzMTM program.

The first key theme, roles and responsibilities of RAzMTM participants, was interesting from a professional practice perspective. Over the last decade or so, the pharmacy profession has sought to expand the role of pharmacists to make better use of their clinical skills. ${ }^{12}$ Pharmacists and pharmacy interns in this study expressed a clear understanding of their role and responsibilities in this program through several examples, which demonstrated a greater focus on using their clinical knowledge to optimize medication therapy rather than just preparing and dispensing medications. They were also able to advance their professional careers as a result of participating in this program, for example, by learning new clinical knowledge or serving as a residency preceptor. The other professions represented in this study (nurse, compliance manager, and promotoras) also had a strong sense of their roles and identified opportunities for professional growth.

Another important finding from this study was the emphasis placed on working collaboratively with other professions. Other recent studies of novel health care services have also highlighted the importance of interprofessional collaboration for a successful program to improve health outcomes. ${ }^{13}$ In 2018, Taylor et al. explored physician referral to telepharmacy MTM services using an in-person care coordinator (not a promotora) as an intermediary. The current study supports these findings and provides another example of effective interprofessional collaboration to improve health outcomes.

Perhaps most importantly, participants articulated several examples that demonstrated the benefits of the 
RAzMTM program for health professionals. This typically led to a greater understanding of each other's roles and may have led to improved health outcomes for patients. For example, the pharmacist was able to work with a promotora to understand how patients are actually using medications and to identify any issues, and then communicate via the promotora to improve medication therapy and obtain better health outcomes.

Along with the benefits of the program, participants suggested areas where the program could be improved. The first recommendation, to resolve scheduling issues, arose due to promotoras having to travel to patients' homes and then finding that the patients and/or the pharmacist were unavailable. A system to improve the scheduling of appointments that works for all stakeholders, while being respectful of everyone's time, is recommended. Offering out-of-hours (e.g., evening or weekend) appointments may be a solution.

A second recommendation was to involve more physicians and other primary care providers in the program. This may have benefits by improving the acceptance of pharmacist recommendations, which has previously been reported as a barrier to the value of such programs, ${ }^{7}$ yet conversely may cause additional challenges from a scheduling perspective. However, the findings from this study, including the benefits to both patients and professionals, as well as the opportunities to further improve the program, may be beneficial for others who are considering setting up a similar interprofessional, collaborative telehealth program for rural patients.

\section{LIMITATIONS}

Limitations of this study included susceptibility to recall bias given that data were self-reported, and a small sample size reflective of the small size of the RAzMTM program staff that limits the generalizability of these results. In addition, length of service in the program may have also influenced participant perceptions.

\section{Conclusions}

These focus group results suggest that a telephonic MTM service for a Spanish-speaking rural population, using an academic-community partnership between health care professionals and promotoras, was positively received by the health care professionals who participated in the RAzMTM project. Future work is needed for continued improvement of strategies to enhance interprofessional relationships between pharmacy staff and promotoras in patient chronic disease management. Also, future studies should explore the connection between promotora-assisted MTM services and improved patient outcomes.

\section{DISCLOSURES}

This project was supported by the Grant or Cooperative Agreement Number DP004793, funded by the Centers for Disease Control and Prevention. Its contents are solely the responsibility of the authors and do not necessarily represent the official views of the Centers for Disease Control and Prevention or the Department of Health and Human Services. This work also was supported, in part, by SinfoniaRx.

Axon, Taylor, and Warholak received funding from SinfoniaRx. Axon reports grants from Tabula Rasa Op-Co, Merck \& Co, Pharmacy Quality Alliance, Arizona Department of Health, and American Association of Colleges of Pharmacy, outside the submitted work. Warholak and Taylor received funding from Arizona Department of Health Services as part of a contract, outside the submitted work. Vaffis reports funding from Merck and Pharmacy Quality Alliance.

This study was presented as a poster at the American Society of HealthSystem Pharmacists Summer Meetings \& Exhibition (June 10-12, 2019, Boston, MA) and as a podium presentation at the Arizona Pharmacy Association Southwestern
States Residency Conference (June 14, 2019, Phoenix, AZ).

\section{ACKNOWLEDGMENTS}

The authors acknowledge Teresa Manygoats, MPA, for her contributions to this project.

\section{REFERENCES}

1. Isetts BJ, Schondelmeyer SW, Artz MB, et al. Clinical and economic outcomes of medication therapy management services: the Minnesota experience. J Am Pharm Assoc (2003). 2008;48(2):203-14.

2. Ramalho de Oliveira D, Brummel AR, Miller DB. Medication therapy management: 10 years of experience in a large integrated health care system. J Manag Care Pharm. 2010;16(3):185-95.

doi: 10.18553/jmcp.2020.26.9.1057

3. Ward MA, Xu Y. Pharmacist-provided telephonic medication therapy management in an MAPD plan. Am J Manag Care. 2011;17(10):399-409.

4. Centers for Medicare \& Medicaid Services. 2018 Medicare Part D Medication Therapy Management (MTM) Programs. Fact sheet. August 20, 2018. Accessed September 27, 2020. https://www.cms.gov/Medicare/ Prescription-Drug-Coverage/ PrescriptionDrugCovContra/Downloads/ CY2018-MTM-Fact-Sheet.pdf

5. Medicare Prescription Drug, Improvement, and Modernization Act of 2003. Public Law 108-173. December 8, 2003. Accessed September 27, 2020. https:// www.govinfo.gov/content/pkg/PLAW108publ173/pdf/PLAW-108publ173.pdf

6. Hall-Lipsy E, Anderson EJ, Taylor AM, et al. Community health worker perspectives of an academic community medication therapy management collaboration. $J$ Am Pharm Assoc (2003). 2020;60(3):475-80

7. Brownstein JN, Allen C. Addressing chronic disease through community health workers: a policy and systems level approach. Second edition. April 2015. Accessed September 27, 2020. https:// www.cdc.gov/dhdsp/docs/chw brief.pdf 
8. Johnson M, Jastrzab R, Tate J, et al. Evaluation of an academic-community partnership to implement MTM services in rural communities to improve pharmaceutical care for patients with diabetes and/or hypertension. J Manag Care Spec Pharm. 2018;24(2):132-41. doi: 10.18553/ jmcp.2018.24.2.132

9. Sharp LK, Tilton JJ, Touchette DR, et al. Community health workers supporting clinical pharmacists in diabetes management: a randomized controlled trial. Pharmacotherapy. 2018;38(1):58-68.
10. Taylor AM, Axon DR, Campbell P, et al. What patients know about services to help manage chronic diseases and medications: findings from focus groups on medication therapy management. J Manag Care Spec Pharm. 2018;24(9):904-10. doi: 10.18553/jmcp.2018.24.9.904

11. Hancock ME, Amankwaa L, Revell MA, Mueller D. Focus group data saturation: a new approach to data analysis. Qual Rep. 2016;21(11):2124-30. Accessed September 27, 2020. https://nsuworks.nova.edu/cgi/ viewcontent.cgi?article $=2330 \&$ context $=$ tqr
12. American College of Clinical Pharmacy. A vision of pharmacy's future roles, responsibilities, and manpower needs in the United States. Pharmacotherapy. 2000;20(8):991-1020.

13. Taylor AM, Bingham J, Schussel K, et al. Integrating innovative telehealth solutions into an interprofessional team-delivered chronic care management pilot program. J Manag Care Spec Pharm. 2018;24(8):813-18. doi: 10.18553/jmcp.2018.24.8.813 